\title{
Qualitative exploration of the factors influencing the use of dietary supplements in Iranian women: introduction to areas of focus for developing interventions
}

\author{
Akramsadat Hoseini \\ Iran University of Medical Sciences: Tehran University of Medical Sciences \\ Tahereh Dehdari ( $\nabla$ mrs13621362@yahoo.com ) \\ https://orcid.org/0000-0002-5670-3077 \\ Mahnaz Solhi \\ Iran University of Medical Sciences: Tehran University of Medical Sciences \\ Seyedeh Tayebeh Rahideh \\ Iran University of Medical Sciences: Tehran University of Medical Sciences \\ Leila Janani \\ Iran University of Medical Sciences: Tehran University of Medical Sciences
}

Iran University of Medical Sciences and Health Services: Tehran University of Medical Sciences

\section{Research article}

Keywords: Experiences, qualitative research, dietary supplements, determinants, Iran

Posted Date: October 23rd, 2020

DOI: https://doi.org/10.21203/rs.3.rs-96331/v1

License: (c) (1) This work is licensed under a Creative Commons Attribution 4.0 International License.

Read Full License

Version of Record: A version of this preprint was published at Heliyon on April 1st, 2021. See the published version at https://doi.org/10.1016/j.heliyon.2021.e06672. 


\section{Abstract}

Background: Literature shows that the consumption of Dietary Supplements (DS) is more common in Iran. This study aimed to explore the experiences of a sample of Iranian women regarding the factors influencing the use of DS.

Methods: This qualitative content analysis study was conducted in Qods city, Tehran province, Iran from January to March 2020. Forty-two semi-structured in-depth interviews were performed with women. The participants were asked about their experiences about the determinants of the consumption of DS. After the first round of the interviews was done, we performed content analysis of the data and continued up to data saturation.

Results: Two main themes including personal factors (with 5 subthemes including sociodemographic characteristics, perceived benefits of DS, history of illness, physiological conditions, and lifestyle factors) and socio-economic factors (with 3 subthemes including subjective norms, the price of food and commercial considerations of the sectors involved in the production and sale of DS) emerged as the experiences of the participants as to the intake of DS.

Conclusions: These variables may suggest areas which need to be focused on for performing more effective interventions to affect appropriate consumption of DS in Iran.

\section{Background}

All over the world, the use of dietary supplements (DS), especially multivitamin-mineral products, is on increase and a large number of people use them routinely (1-4). In this regard, the result of a study in Iran showed that the prevalence of the use of DS among Iranian women and men was $43.2 \%$ and $20.4 \%$, respectively [1]. Also, Gahche et al. indicated that $70 \%$ of older adults in the United States had used 1 DS in the past 30 days; $54 \%$ of them used 1 or 2 products, and $29 \%$ used $\geq 4$ products [2]. Sekhri and Kaur reported that $68.3 \%$ of the general public in India used multivitamin supplements [3]. In some countries, the use of DS has doubled in the past several years [5].

Despite the benefits of using some DS in people who need to receive it [6], these products are mostly selfprescribed with no input from informed medical sources such as doctors, or pharmacists [7]. DS may directly cause toxic reactions or may interact with other supplements or prescription medications. Some of DS have been contaminated with heavy metals [8]. The result of a study showed that about 23,000 emergency department visits in the United States annually were associated with the side effects of DS, such as cardiovascular manifestations [9]. In a study, mortality has been attributed to the use of some vitamins and minerals, such as iron [10]. The result of a study showed that high calcium use was associated with increased risk of coronary artery calcification [11]. Moreover, the combination of folic acid and $B_{12}$ increases the risk of death from all causes and cancers [12]. Unfortunately, most of the consumers of DS are unaware about its possible adverse effects or medication-supplement interactions [13]. 
Taking DS is influenced by such factors as gender, educational level, age, history of chronic diseases, body mass index, and belief about the benefits of DS $[3,14,15]$. However, additional information regarding the reasons behind the use of DS in each country is required to develop appropriate and effective interventions for its correct usage [5].

Despite the excessive use of DS in Iran [16,17], to the best of our knowledge, no study has been conducted to determine the reasons for the use of DS from perspective of Iranian consumers. Therefore, the objective of the present study was to explore the experiences of a sample of Iranian women as to the factors influencing the use of DS.

\section{Materials And Methods}

\section{Design and participants}

A qualitative content analysis design (conventional method) was used to identify the experiences of a sample of women regarding the factors influencing the use of DS in Qods city, Tehran province, Iran, from January to March 2020. Those participants who used DS were selected. In this study, the inclusion criteria were: a) female sex, b) Iranian nationality, c) residence in Qods city, d) willingness to participate in the present study and share their related experiences. All the participants were informed about the objectives of the study and signed the informed consent form. The ethics committee of Iran University of Medical Sciences approved the protocol of the present study (\# IR.IUMS.REC.1397.935).

\section{Data Collection}

Semi-structured interviews were done with the participants. With the permission of the study participants, the interviews were recorded via audiotape and transcribed verbatim by one of the researchers of the study. The interviews were conducted in one of the primary health care facilities of Qods city. The time of conducting interviews was arranged with the participants' consent. Each interview lasted between 20 and $25 \mathrm{~min}$. The topic of interviews included the history of using DS by the study participants and the factors

affecting the use of DS by them. Sampling was continued until we reached data saturation. Demographic characteristics of the participants were collected by a self-administered questionnaire.

\section{Data analysis}

The interviews were first recorded and then rewritten word for word. Content analysis was done through review of the versions in four stages. Through reviewing of the interviews, a general impression was obtained and then based on the statements of the individuals, the meaning of the units was obtained and codded. The researchers identified the initial code in the data and then evaluated the degree of similarity. Through further review of the versions, the initial codes were merged to determine the main content of the data; the emerged categories were compared and scrutinized during the interviews to show the categories that revealed subtle differences in data. Data were collected until the saturation phase was achieved [18]. 
To obtain in-depth data, maximum sampling was employed according to age, and level of education. The study participants' agreement for long-term interaction with the researchers of the present study was achieved. Member check was carried out with 15 participants to ensure that the analysis reflected their actual experiences [19].

\section{Results}

Forty-two participants were interviewed. The demographic features of the participants are presented in Table 1. After data analysis, two main themes including a) personal factors and b) socio-economic factors emerged as the experience of the study participants regarding the reasons for using DS. The categories and sub-categories are summarized in Table 2. 
Table 1

Demographic characteristics of the study participants (n $=42$ )

\begin{tabular}{|lclll|}
\hline Variables & $n$ & $\%$ & Mean & SD \\
\hline Age & & & 38.90 & $17 / 6$ \\
\hline Sex(Female) & 42 & 100 & & \\
\hline Marital status & & & & \\
\hline Single & 17 & 40.47 & \\
\hline Married & 25 & 59.52 & \\
\hline Educational level & & & \\
\hline Illiterate & 1 & 2.38 & \\
\hline$\leq 12$ th grade & 8 & 19.04 & \\
\hline 12th grade< & 33 & 78.57 & \\
\hline Employment status & & \\
\hline Self-employed & 2 & 4.76 \\
\hline Employee & 8 & 19.04 \\
\hline Casual laborer & 2 & 4.76 \\
\hline Household duties & 25 & 59.52 \\
\hline Student & 5 & 11.90 \\
\hline Consumption dietary supplements & \\
\hline Sometimes & 3 & 7.14 \\
\hline Often & 8 & 19.04 & \\
\hline Always & 31 & 73.80 & \\
\hline
\end{tabular}


Table 2

Categorization of the themes and subthemes

\section{Personal factors}

a) Perceived benefits of dietary supplements

1. Increasing fitness and weight loss

2. Reducing hair loss

3. Increasing skin health and beauty

4. Improving mood (e.g. anxiety and anger)

5. Reducing the body's needs to unhealthy or unsafe foods

6. Filling the nutritional gaps in the diet

b) History of illness

1. Diabetes

2. Intolerance of lactose

3. Hyperlipidemia

4. Autoimmune diseases

5. Persistent weakness

6. Muscle ache

7. Anemia

c) Physiological condition

1. Pregnancy or planning to get pregnant

2. Lactation

3. Oral contraceptive use

d) Sociodemographic characteristics

1. Age

2. Household income

3. Educational level

4. Urbanization

e) Lifestyle factors

1. Tobacco smoking

2. Having physical activity

3. Trying to weight

\section{Socio-economic factors}




\section{Personal factors}

a) Subjective norms

1. The use of dietary supplements by people around (including family members, co-workers, neighbors, friends, and others)

2. Encouragement to use dietary supplements by doctors, health care providers, pharmacy staff, family members and mass media

b) The price of food

1. High price of fruits and vegetable

2. High price of meat and protein

3. High price of dairy products

4. High price of organic or healthy products

c) Commercial considerations of the sectors involved in the production and sale of dietary supplements
1. Economic benefits of the sale of dietary supplement by dietary supplement industry

2. Economic benefits of the sale of dietary supplement by pharmacies and drug stores

\section{Subthemes of personal factors}

Personal factors with 5 subthemes including perceived benefits of DS, history of illness, physiological condition, sociodempgraphic characteristics, and lifestyle factors were identified as one of the influencing factors for the use of DS among the participants.

The subjects indicated that perceived benefits of DS may lead to increased consumption. They told that DS may increase fitness, reduce hair loss, increase the skin health and its beauty, improve the mood, reduce the body's needs to unhealthy or unsafe foods, and fill nutrient gaps in the diet. They stated:

'I have been taking DS such as multivitamin, selenium, zinc and vitamin C for a long time... Due to the use of these supplements, my skin is very clear and nice'(F37), 'When I take DS, I feel that my body becomes stronger and fresher...' (F23), 'DS may prevent any illness or pain'(F32), '... the consumption of DS has positive effects on the mood, mind, concentration, nervous and mental health, and brain function'(F50), '... I was stressed and anxious... one of my colleagues said that you probably have anemia or lack of vitamin in your body and I started to take DS'(F29), 'To prevent carcinogenic and pathogenic effects of environmental pollution, parasites and free radicals on my body, I take multivitamins, zinc, selenium and calcium'(F39), 'The quality of foods is decreasing nowadays. I feel that foods cannot meet my body's nutritional needs...; therefore, I, my children, and other relatives need to take DS'(F27), 'Since fruits and vegetables are contaminated with toxins, they cannot provide the necessary vitamins, fiber and minerals to human body. Therefore, it would be better to use DS (F48). 
From the participants' perspectives, one of the factors affecting the use of DS was history of some illnesses. Many participants stated that the history of illnesses such as diabetes, lactose intolerance, hyperlipidemia, muscle aches, persistent weakness, anemia, and autoimmune diseases may affect the use of DS, 'My immune system is weak... I am often sick. Therefore, I consume multivitamins'(F19), 'I have constant fatigue and weakness and my muscles ache. I feel better when I take DS'(F40), 'I went to the doctor and he said that, due to my weak body anemia, I should take iron supplement. I decided to take iron and folic acid and other multivitamins'(F56), 'My parents have diabetes. I am susceptible to this disease. I avoid a lot of foods, so, I have to take DS'(F37).

A number of participants told that some physiological conditions such as being pregnant or planning for pregnancy, breastfeeding, and using oral contraceptive might influence the use of DS: '/ will not get pregnant. I take supplements like Pharmaton, zinc, selenium, vitamin E, and powders like Ginseng every day to get pregnant ...'(F26), 'I use DS to have a normal and comfortable delivery... and give birth to healthier babies'(F33), 'I used DS during lactation...'(F48), 'Everyone should take vitamin supplements, especially women that use oral contraceptives'(F48), 'When I take oral contraceptive pills, I use DS to prevent nausea and other side effects of these pills'(F37).

Some participants told that sociodemographic characteristics including age, employment status, educational level, household income, and urbanization had significant effects on the use of DS, 'DS should be taken by people aged above 32 years. The intake rates for DS increase with age'(F64), 'Since my and my wife's income and education level are high, we consume DS regularly...'(F48), 'Occupation is a factor influencing the use of DS. I am an employee and do not have enough time to prepare and eat some foods (e.g. salad and vegetable). I prefer to take DS' (F39). 'Those who have a good job and income are more likely to consume one or more DS...' (F47), 'Urbanization may generate more physical and mental concerns. The use of DS is more prevalent among people who reside in urban areas'(F48).

Some participants stated that the use of DS was associated with lifestyle characteristics such as physical activity, tobacco smoking and attempts to control the weight: 'DS increases energy and physical strength. I think they are essential for the body, especially for people who exercise regularly'(F32), 'Given that I'm very obese, I cannot eat all kinds of food. I have decided to lose weight, so I take DS'(F45), 'Because I am a professional swimmer, I take DS regularly'(F19), 'People will have better weight control and fitness if they take DS in addition to exercise and proper nutrition'(F23), 'The use of DS may reduce appetite and lead to better weight control' (F30(, 'Smoking reduces the absorption of vitamins consumed through food. I take DS because I smoke' (F26).

\section{Subthemes of socio-economic factors}

Socio-economic factors with 3 subthemes including subjective norms, the price of food, and large-scale advertisement of DS industry were identified as one of the influencing factors in the use of DS among the participants.

The majority of the participants emphasized the importance of the impact of subjective norms on the use of DS. They mentioned that they were under pressure to use DS and their spouse, mother, sister, friends, 
colleagues and other people around them, pharmacy staff and technicians, health providers and social media encouraged them to use DS, 'My wife takes DS every night. She believes that a woman should always take care of her body and it would be better for you to consume DS...' (F30(, 'My sister and friends introduced the types of DS to me. According to their advice, I use DS to increase my energy and reduce fatigue'(F22), 'Employees of pharmacies highlighted the benefits of DS to persuade people to buy and consume it'(F21), 'The images and labels of the products of DS are so appealing and attractive for me. When I see these packages in the drugstore, instead of buying one supplement, I buy all kinds of them' (F28), 'A large amount of information provided by virtual sites may increase the use of DS'(F30(, 'Some health care providers emphasize that taking DS may prevent aging and disease'(F21).

Some of the participants also talked about the importance of the price of foods in increasing the intake of DS. They mentioned that the price of foods was on increase and they had to use DS, 'Everything is expensive. We can't buy some fruits, vegetables or nuts... We have to use all kinds of multivitamins and supplements'(F29), 'I didn't use any DS in the past years. After increasing the price of dairy products and meat, I take supplements every day'(F30), 'Nutrient-rich foods are more expensive than lower-quality foods. I have to eat multivitamins, zinc, selenium, calcium and so on to meet my body's needs'(F54).

A number of participants told that commercial considerations of the sectors involved in the production and sale of dietary supplements are the factor affecting the use of these supplements, 'The DS industry is so lucrative that various companies are regularly producing new multivitamins and persuade people to consume them' (F33), 'The huge profit of pharmacies and drug stores from the sale of DS increases marketing them. This marketing may enhance the use of DS by people'(F39), 'D rug stores try to sell new $D S$ to people for more profits'(F48).

\section{Discussion}

The results of the present study provided information on the participants' experiences of the factor influencing the use of DS. It is recommended that tailored and effective interventions should be designed to make people aware of the risks of uncontrolled and uncorrected intake of DS in Iran.

Perceived benefits of DS were known as one of the personal factors influencing the use of DS. In the same line, Mohdzaki et al. and Alfawaz et al. showed that looking beautiful and maintaining healthy hair were two of the main reasons for consumption of DS among females [20, 21]. Margit Pajor et al. showed that users believed that DS might improve mental and physical health and reduce health complaints.

They also noted that one of the reasons of using DS by adults was that they believed that the quality and safety of food products might have declined recently; they are of the opinion that food contains considerably lower amounts of vitamins and minerals [22]. In a study by Dickinson et al., it was reported that $42 \%$ of the participants took DS to fill nutrient gaps in their diet [23]. Despite the positive effects of some DSs on the skin and hair health, psychological state, and the reduction of weight [24-26], taking them more than the needs of the body has some adverse effects [27]. Nowadays, given the motivation of most people for fitness and weight loss, a great opportunity has been created for the supplement industry 
to produce and market a wide range of DSs claiming weight loss, while there is evidence of some direct side effects or combination and interactions with other drugs [28]. Women should be advised to consume a balanced, healthy diet, which includes vitamins A, B, C, and E -rich foods and be encouraged to adopt safe weight reduction methods.

In our study, some participants reported that the history of some illnesses might affect the intake of DS. Literature showed that adults who had a history of a chronic disease or those who thought they themselves had got these diseases subjectively had more preference for using DS than those who did not $[29,30]$. In line with these results, Islam et al. showed that "to recover from disease" was the mostly reported reason for using DS among adult population in southern Bangladesh [25]. Bailey et al. found that $18 \%$ of US adults used DS to lower their cholesterol level and have a healthy heart [31]. Salgado et al. found that $10.3 \%$ of Brazilian road runners used DS for their fatigue [32]. Pillay and Pillay also reported that $62.5 \%$ of dietetic students used DS for strengthening their immune system [33]. Considering the history of disease in people may help to identify those in need of education regarding the supplements and the adverse effects of using them through self-description.

Several participants reported that some physiological conditions such as being pregnancy or planning for pregnancy, breastfeeding and oral contraceptive use may influence the use of DS. In the same line, Aronsson et al. and Morin et al. showed that being pregnant with the first child and pregnancy planning were two predictors for the intake of DS in mothers [34,35]. Picciano and McGuire also reported that in North America, half of pregnant or lactating women use some form of DS [36]. Despite the fact the using some DS during pregnancy might be important for maternal and fetal health [6], literature showed that mean intakes of thiamin, riboflavin, niacin, folic acid, vitamins B6, B12, and C, iron, and zinc from DS alone were at or above their respective recommended dietary allowances (RDAs) among pregnant and lactating DS users. About $50 \%$ of pregnant and $40 \%$ of lactating women consume DS based on the recommendation of a health care provider [37]. It is suggested that during pre-pregnancy counseling, the women's diet should be taken into account, and DS should be prescribed to ensure they meet the RDAs for essential nutrients.

Some study participants indicated that sociodemographic characteristics including the age, employment status, educational level, household income, and urbanization may affect the use of DS. Previous studies confirmed that age and educational level variables impacted the use of DS [25,34,38]. In this regard, Cowan et al. demonstrated that the highest income group among US adults were the highest consumers of DS [4]. Austin et al. showed that increased use of DS in US coast guard personnel was associated with high intensity operational occupations [39]. Since the sociodemographic characteristics may determine different behaviors regarding the intake of DS, further research is recommended among other groups with different demographics features.

Some participants indicated that the use of DS was associated with lifestyle characteristics such as the physical activity level, tobacco smoking and desire to control weight. This finding is consistent with those of Bailey et al. and Mullie et al., indicating that DS users were more likely to report exercise or physical 
activity more frequently than non-users [31, 40]. It is worth mentioning that athletes or individuals with high physical activity consume DS for enhancing energy, improving performance, and increasing the level of endurance [32]. Previous studies revealed that $\mathrm{BMI} \geq 25.0$ and $\mathrm{BMI} \geq 30.0 \mathrm{~kg} / \mathrm{m}^{2}$ were recognized as one of the factors influencing the use of DS $[34,41]$. Our participants mentioned that smokers were more likely to take DS than non-smokers. This finding is consistent with those of similar studies that showed using DS was more observed among smokers than non-smokers [42, 43]. Thus, nutritionists or other health care professionals should consider lifestyle as confounders of using DS and are recommended to convince their clients that a balanced diet can meet the needs of physically active people, smokers and those who tend to control their weight. In addition, clients should be made aware that DS must always be used under the supervision of a specialist.

Socio-economic factors with 3 sub-themes emerged as one of the factors that impacted the use DS among the participants. One of the sub-themes was subjective norms. High social pressure to take multivitamin supplements may motivate the females to decide to use it [44]. Both users and even nonusers of DS reported that they had been exposed to different social influences for the intake of DS [22]. Conner et al. noted that the media had powerful influence on a person's decision to consume DS [45]. Given that the social pressure is a facilitator in starting and continuing the use of DS, health care professionals should be aware of the culture and attitude of the community towards DS intake and are recommended to educate the individuals through mass media about benefits as well as complications of DS.

The second socio-economic factor that influenced DS consumption among the study participants was high price of food. Rao et al. in a systematic review stated that healthier choices of food groups, especially for meats/proteins, were more expensive per serving than the less healthy ones [46]. Studies have shown that the increase of price affects the quantity and quality of food consumed. For example, the results of a study by a colleague showed that increasing the price of different food groups such as meat and serials was one of the reasons for reduction of their consumption [47]. French demonstrated that reduction in the price of healthier food products such as fruits and vegetables may lead to a fourfold increase in their consumption [48]. Given the fact that for a large number of low-income women the cost of food is an obstacle to buying and eating healthier foods, opportunities for reducing financial barriers to healthy diet may decrease the intake of DS. Thus, increasing food security should be more considered by policy- makers.

The third socio-economic factor that was reported to influence DS consumption among the study participants was commercial considerations of the sectors involved in the production and sale of DS. They stated that the profits from the sale of DS caused these industries to do a lot of marketing. Literature showed that the reasons for DS intake were closely aligned with marketed claims [49]. DS industries heavily rely on marketing tools to sway consumer opinion [50]. Given that the DS market in Iran is experiencing a significant growth [51], the authorities are suggested to take measures to ensure that advertising claims about the health benefits of DS is correct. 


\section{Conclusion}

The results of the present study showed that the use of DS might be affected by certain personal and socio-economic factors. This research provided the basis for consumer education about the benefits and adverse effects of DS according to sociodemographic considerations, physiological conditions, lifestyle factors, history of illnesses, and socio-economics factors.

\section{List Of Abbreviations}

DS: Dietary supplements, RDAs: Recommended Dietary Allowances

\section{Declarations}

\section{Ethics approval and consent to participate}

The study was approved by the ethics committee of Iran University of Medical Sciences, Tehran, Iran (Ethical Approval Code: IR.IUMS.REC.1397.935). All participants were informed about the study objectives and completed a consent form. They were assured that their voices were kept secured and coded according to each participant's identification number.

\section{Consent for publication}

Not applicable.

\section{Availability of data and materials}

Data sharing is not applicable to this article as no datasets were generated or analysed during the current study.

\section{Competing interests}

The authors declare that they have no competing interests.

\section{Funding}

All costs of this research have been paid by the study researchers.

\section{Authors' contributions}

TD, AH, MS, TR and LG contributed to the design of the study, data collection, interpretation of data and prepared the manuscript.

\section{Acknowledgments}

We appreciate the participants involved in the study for their cooperation. 


\section{Authors' information}

${ }^{1}$ Department of Education and Health Promotion, School of Health, Iran University of Medical Sciences, Tehran, Iran

${ }^{2}$ Department of Nutrition, School of Health, Iran University of Medical Sciences, Tehran, Iran

${ }^{3}$ Department of Biostatistics, School of Health, Iran University of Medical Sciences, Tehran, Iran

\section{References}

1. Sotoudeh G, Kabiri S, Yeganeh HS, Koohdani F, Khajehnasiri F, Khosravi S. Predictors of dietary supplement usage among medical interns of Tehran university of medical sciences. Journal of health, population, and nutrition. 2015;33:68.

2. Gahche JJ, Bailey RL, Potischman N, Dwyer JT. Dietary supplement use was very high among older adults in the United States in 2011-2014. The Journal of nutrition. 2017;147:1968-76.

3. Sekhri K, Kaur K. Public knowledge, use and attitude toward multivitamin supplementation: A crosssectional study among general public. International Journal of Applied and Basic Medical Research. 2014;4:77.

4. Cowan AE, Jun S, Gahche JJ, Tooze JA, Dwyer JT, Eicher-Miller HA, Bhadra A, Guenther PM, Potischman N, Dodd KW, Bailey RL. Dietary supplement use differs by socioeconomic and healthrelated characteristics among US adults, NHANES 2011-2014. Nutrients. 2018;10:1114.

5. Pajor EM, Eggers SM, Curfs KC, Oenema A, De Vries H. Why do Dutch people use dietary supplements? Exploring the role of socio-cognitive and psychosocial determinants. Appetite. 2017;114:161-8.

6. Van Sande H, Jacquemyn Y, Karepouan N, Ajaji M. Vitamin B12 in pregnancy: Maternal and fetal/neonatal effects-A review. Open Journal of Obstetrics and Gynecology. 2013;13:2013.

7. Lam A, Bradley G. Use of self-prescribed nonprescription medications and dietary supplements among assisted living facility residents. Journal of the American Pharmacists Association. 2006;46:574-81.

8. Binns CW, Lee MK, Lee AH. Problems and prospects: public health regulation of dietary supplements. Annual review of public health. 2018;39:403-20.

9. Geller Al, Shehab N, Weidle NJ, Lovegrove MC, Wolpert BJ, Timbo BB, Mozersky RP, Budnitz DS. Emergency department visits for adverse events related to dietary supplements. New England Journal of Medicine. 2015;373:1531-40.

10. Mursu J, Robien K, Harnack LJ, Park K, Jacobs DR. Dietary supplements and mortality rate in older women: the lowa Women's Health Study. Archives of internal medicine. 2011;171:1625-33.

11. Anderson JJ, Kruszka B, Delaney JA, He K, Burke GL, Alonso A, Bild DE, Budoff M, Michos ED. Calcium intake from diet and supplements and the risk of coronary artery calcification and its 
progression among older adults: 10-year follow-up of the Multi-Ethnic Study of Atherosclerosis (MESA). Journal of the American Heart Association. 2016;5:e003815.

12. Ebbing M, Bønaa KH, Nygård O, Arnesen E, Ueland PM, Nordrehaug JE, Rasmussen K, Njølstad I, Refsum H, Nilsen DW, Tverdal A. Cancer incidence and mortality after treatment with folic acid and vitamin B12. Jama. 2009;302:2119-26.

13. Saini S, Hasan N. A survey of multivitamin supplement knowledge, attitude, and use in the urban community of Bikaner, Rajasthan. CHRISMED Journal of Health and Research. 2015;2:329.

14. Archer SL, Stamler J, Moag-Stahlberg A, Van Horn L, Garside D, Chan Q, Buffington JJ, Dyer AR. Association of dietary supplement use with specific micronutrient intakes among middle-aged American men and women: the INTERMAP Study. Journal of the American Dietetic Association. 2005;105:1106-14.

15. Lieberman HR, Marriott BP, Williams C, Judelson DA, Glickman EL, Geiselman PJ, Dotson L, Mahoney CR. Patterns of dietary supplement use among college students. Clinical Nutrition. 2015;34:976-85.

16. Najmabadi S, Nojomi M. Nutritional supplement use among adults in different areas of west Tehran. Iranian Journal of Endocrinology and Metabolism. 2010;12:4.

17. Baygi F, Sotoudeh G, Qorbani M, Sadrzadeh-Yeganeh H, Rahimi A, Koohdani F, Asayesh H. Predictors of dietary supplement use among female health workers in Tehran. Journal of Diabetes \& Metabolic Disorders. 2013;121:26.

18. Elo S, Kyngäs $\mathrm{H}$. The qualitative content analysis process. Journal of advanced nursing. 2008;62:107-15.

19. Cypress BS. Rigor or reliability and validity in qualitative research: Perspectives, strategies, reconceptualization, and recommendations. Dimensions of Critical Care Nursing. 2017;36:253-63.

20. Zaki A, Rasidi N, Awaluddin SM, Guat Hiong T, Ismail H, Safiza N. Prevalence and characteristic of dietary supplement users in Malaysia: Data from the Malaysian Adult Nutrition Survey (MANS) 2014. Published by Canadian Center of Science and Education. 2018;10:12.

21. Alfawaz H, Khan N, Alfaifi A, Shahrani FM, Al Tameem HM, Al Otaibi SF, Abudigin WI, Al-Shayaa MS, Al-Ghanim SA, Al-Daghri NM. Prevalence of dietary supplement use and associated factors among female college students in Saudi Arabia. BMC women's health. 2017;17:116.

22. Pajor EM, Oenema A, Eggers SM, de Vries H. Exploring beliefs about dietary supplement use: focus group discussions with Dutch adults. Public Health Nutrition. 2017;20:2694-705.

23. Dickinson A, Blatman J, El-Dash N, Franco JC. Consumer usage and reasons for using dietary supplements: report of a series of surveys. Journal of the American College of Nutrition. 2014;33:176-82.

24. Piccardi N, Manissier P. Nutrition and nutritional supplementation: Impact on skin health and beauty. Dermato-endocrinology. 2009;1:271-4.

25. Islam M, Hasan MT, Al-Fuad MS, Al Mamun MA, Biswas BK, Razon AH, Roy RK. Dietary Supplements Use and Associated Determinants Among Adult Population in Southern Bangladesh. American Journal of Food Science and Nutrition Research. 2018;5:64-70. 
26. Geller SE, Studee L. Botanical and dietary supplements for mood and anxiety in menopausal women. Menopause. 2007;14:541-9.

27. Guo EL, Katta R. Diet and hair loss: effects of nutrient deficiency and supplement use. Dermatology practical \& conceptual. 2017;7:1.

28. Temple NJ. The marketing of dietary supplements: a Canadian perspective. Current Nutrition Reports. 2013;2:167-73.

29. Lee JS, Kim J. Factors affecting the use of dietary supplements by Korean adults: data from the Korean National Health and Nutrition Examination Survey III. Journal of the American Dietetic Association. 2009;109:1599-605.

30. He YN, Yang Z, Xu J, Sha YM, Ren ZY, Pang XH, Zeng G, Zhai FY. Analysis on influence factors of dietary supplement used in population aged above 45 years in Beijing. Zhonghua yu fang yi xue za zhi [Chinese Journal of Preventive Medicine]. 2008;42:823-6.

31. Bailey RL, Gahche JJ, Miller PE, Thomas PR, Dwyer JT. Why US adults use dietary supplements. JAMA internal medicine. 2013;173:355-61.

32. Salgado JV, Lollo PC, Amaya-Farfan J, Chacon-Mikahil MP. Dietary supplement usage and motivation in Brazilian road runners. Journal of the International Society of Sports Nutrition. 2014;11:1-5.

33. Pillay L, Pillay K. Dietary supplement use among dietetics students at the University of KwaZuluNatal. Health SA Gesondheid. 2019;24.

34. Aronsson CA, Vehik K, Yang J, Uusitalo U, Hay K, Joslowski G, Riikonen A, Ballard L, Virtanen SM, Norris JM. Use of dietary supplements in pregnant women in relation to sociodemographic factors-a report from The Environmental Determinants of Diabetes in the Young (TEDDY) study. Public health nutrition. 2013;16:1390-402.

35. Morin P, De Wals P, St-Cyr-Tribble D, Niyonsenga T, Payette H. Pregnancy planning: a determinant of folic acid supplements use for the primary prevention of neural tube defects. Canadian journal of public health. 2002;93:259-63.

36. Picciano MF, McGuire MK. Use of dietary supplements by pregnant and lactating women in North America. The American journal of clinical nutrition. 2009;89:663S-7S.

37. Branum AM, Bailey R, Singer BJ. Dietary supplement use and folate status during pregnancy in the United States. The Journal of nutrition. 2013;143:486-92.

38. Jun S, Gahche JJ, Potischman N, Dwyer JT, Guenther PM, Sauder KA, Bailey RL. Dietary supplement use and its micronutrient contribution during pregnancy and lactation in the United States. Obstetrics \& Gynecology. 2020;135:623-33.

39. Austin KG, Price LL, McGraw SM, Lieberman HR. Predictors of dietary supplement use by US Coast Guard personnel. PLoS One. 2015;10:e0133006.

40. Mullie P, Clarys P, Hulens M, Vansant G. Socioeconomic, health, and dietary determinants of multivitamin supplements use in Belgium. International journal of public health. 2011;56:289-94. 
41. Knapik JJ, Trone DW, Austin KG, Steelman RA, Farina EK, Lieberman HR. Prevalence, adverse events, and factors associated with dietary supplement and nutritional supplement use by US Navy and Marine Corps personnel. Journal of the Academy of Nutrition and Dietetics. 2016;116:1423-42.

42. Lacerda FM, Carvalho WR, Hortegal EV, Cabral NA, Veloso HJ. Factors associated with dietary supplement use by people who exercise at gyms. Revista de saude publica. 2015;49:63.

43. Lieberman HR, Marriott BP, Williams C, Judelson DA, Glickman EL, Geiselman PJ, Dotson L, Mahoney CR. Patterns of dietary supplement use among college students. Clinical Nutrition. 2015;34:976-85.

44. Pawlak R, Brown D, Meyer MK, Connell C, Yadrick K, Johnson JT, Blackwell A. Theory of planned behavior and multivitamin supplement use in Caucasian college females. The journal of primary prevention. 2008;29:57-71.

45. Conner M, Kirk SF, Cade JE, Barrett JH. Environmental influences: factors influencing a woman's decision to use dietary supplements. The Journal of nutrition. 2003;133:1978S-82S.

46. Rao M, Afshin A, Singh G, Mozaffarian D. Do healthier foods and diet patterns cost more than less healthy options? A systematic review and meta-analysis. BMJ open. 2013;3.

47. Lee JH, Lim KF, Yong KY. Factors Influencing Purchase Intention towards Dietary Supplement Products among Young Adults(Doctoral dissertation, UTAR). 2016.

48. French SA. Pricing effects on food choices. The Journal of nutrition. 2003;133:841S-3S.

49. Barnes K, Ball L, Desbrow B, Alsharairi N, Ahmed F. Consumption and reasons for use of dietary supplements in an Australian university population. Nutrition. 2016;32:524-30.

50. Ghosh N, Sen CK. The Promise of Dietary Supplements: Research Rigor and Marketing Claims. InNutrition and Enhanced Sports Performance 2019 : 759-766).

51. Khosroshahi AG, Saiyarsarai P, Yektadoost A, Jamshidi A, Asl AA, Kebriaeezadeh A. Dietary Supplements Market Size Analysis in Iran From 2011 to 2015. Journal of Pharmacoeconomics and Pharmaceutical Management. 2017;3:41-7. 